\title{
Autoradiographic Localization of Tryptamine Binding Sites in the Rat and Dog Central Nervous System
}

\author{
James K. McCormack, Alvin J. Beitz, and Alice A. Larson \\ Department of Veterinary Biology, University of Minnesota, St. Paul, Minnesota 55108
}

Tryptamine, an endogenous trace amine, is currently postulated to be a neuromodulator or neurotransmitter in the mammalian CNS. High-affinity binding sites have been described for tryptamine in rat brain homogenate preparations. The present study further characterizes tryptamine binding throughout the CNS and delineates its distribution using in vitro receptor binding in conjunction with autoradiographic techniques. Saturation studies on $20-\mu \mathrm{m}$-thick brain sections suggest a single class of binding sites (Hill coefficient $=0.97 \pm 0.04$ ) with a high affinity $\left(K_{D}=4.79 \pm 1.55 \mathrm{nM}\right)$. In competition studies, kynuramine and tetrahydrobetacarboline significantly inhibited $\mathbf{H}^{3}$-tryptamine binding while serotonin, dopamine, and phenylethylamine failed to significantly inhibit it. The most potent inhibitor of $\mathbf{H}^{3}$-tryptamine binding was tryptamine $\left(K_{t}=4.19 \pm 2.13 \mathrm{nM}\right)$. In rat brain sections processed for in vitro autoradiography, highest binding occurred in the following limbic structures: the accumbens nucleus, the amygdalohippocampal area, the lateral septal nucleus, the entorhinal cortex, and the anterior olfactory nucleus. At diencephalic levels, the highest binding was observed in the reuniens thalamic nucleus, the paraventricular thalamic nucleus, the medial habenular nucleus, the central medial thalamic nucleus, and the arcuate hypothalamic nucleus. In the midbrain of the rat, binding was most notable in the interpeduncular nucleus, the superficial layer of the superior colliculus, the periaqueductal gray, and the paranigral nucleus. In the lower brain stem of the dog, binding was evident in the external cuneate nucleus, the spinal trigeminal nucleus, and in the region of the solitary nucleus. Binding was also present in both the ventral and dorsal horns of the canine spinal cord. Tryptamine binding sites appear widely distributed throughout the CNS, exhibiting the highest densities of binding in the more rostral portions of the brain.

Tryptamine is present in all major brain regions in all species examined thus far (Marsden and Curzon, 1974; Martin et al., 1972; Philips et al., 1974; Saavedra and Axelrod, 1972; Sloan et al., 1975; Snodgrass and Horn, 1973). Mass spectrometric quantification reveals that the concentration of tryptamine in the caudate $(2.93 \mathrm{ng} / \mathrm{gm})$ is almost six times that of whole brain, and concentrations in the hypothalamus are almost double that of whole brain (Philips et al., 1974). Tryptamine has been previously postulated to be a neuromodulator or neurotransmitter in the mammalian CNS (Frankhuijzen and Bonta, 1974; Quock and Weick, 1978; Vane et al., 1961). Both supporting and op-

Received Apr. 2, 1985; revised June 17, 1985; accepted July 8, 1985.

This work was supported by NIH Grants NS19208 and NS17407, NSF Grant BNS83-11214, as well as by a grant from the American Veterinary Medical Association.

Correspondence should be sent to Dr. Alice A. Larson, Dept. of Veterinary Biology, 295 Animal Science/Veterinary Medicine Building, St. Paul, MN 55108 Copyright (c) 1986 Society for Neuroscience $0270-6474 / 86 / 010094-08 \$ 02.00 / 0$ posing evidence for such a role has been reviewed by Jones (1982).

More recently, additional supporting evidence that documents a high-affinity binding site for $\mathrm{H}^{3}$-tryptamine in rat brain homogenates has been presented (Cascio and Kellar, 1982; Kellar and Cascio, 1982). Since then, other investigators have also demonstrated that tryptamine binding sites are present in the CNS and are distinct from those of serotonin binding sitcs (Rommelspacher and Kaufmann, 1983; Wood et al., 1984). Tryptamine binding has been found to be strongly inhibited by beta-carbolines (Cascio and Kellar, 1983; Rommelspacher and Kaufmann, 1983; Wood et al., 1984), kynuramine (Charlton et al., 1984), and derivatives of phenylethylamine (PE $\Lambda$ ) (Cascio and Kellar, 1983; Martin et al., 1984). This suggests that several endogenously found compounds are possible ligands for the tryptamine binding site.

All the binding studies described above have been performed on brain homogenate preparations. Although these homogenate studies have provided data on tryptamine binding in large brain regions, they fail to delineate the localization of tryptaminebinding sites among brain nuclear groups. The in vitro autoradiographic technique developed by Young and Kuhar (1979) allows precise delineation of binding sites among brain nuclei. Two preliminary reports have described the use of this technique to elucidate the localization of tryptamine binding sites in the CNS (McCormack et al., 1983; Perry et al., 1982). The purpose of the present investigation is to employ in vitro autoradiographic technique to map tryptamine binding sites in the rat and dog CNS.

\section{Materials and Methods}

Male Sprague-Dawley rats, weighing between 250 and $300 \mathrm{gm}$, were anesthetized with chloral hydrate and perfused transcardially with ice cold isotonic saline. Brains were immediately removed, slowly frozen to $-20^{\circ} \mathrm{C}$, and used for binding studies within $24 \mathrm{hr}$. Dogs of either sex, weighing between 10 and $15 \mathrm{~kg}$, were premedicated with atropine and acetylpromazine and anesthetized with pentobarbital. Dogs were cannulated in the carotid artery and perfused with ice cold isotonic saline over a $30 \mathrm{~min}$ period. The spinal cord and lower brain stem were removed and slowly frozen to $-20^{\circ} \mathrm{C}$ after gross dissection into the following six regions: medulla, $\mathrm{C} 1$ to $\mathrm{C} 5, \mathrm{C} 6$ to $\mathrm{T} 2, \mathrm{~T} 3$ to $\mathrm{T} 13, \mathrm{~L} 1$ to $\mathrm{L} 3$, and $\mathrm{L} 4$ to $\mathrm{S} 3$.

To establish appropriate biochemical parameters for $\mathrm{H}^{3}$-tryptamine binding, rat brains were first sectioned at $20 \mu \mathrm{m}$ on an American Optical cryostat at $-20^{\circ} \mathrm{C}$. Serial sections from the rostral commissure through the caudal hippocampus were thaw-mounted onto clean glass slides and refrozen until used. Slide-mounted sections were then placed in preincubation baths for 5 and $2 \mathrm{~min}$ each, transferred to an incubation bath for $60 \mathrm{~min}$, and subsequently washed twice in trizma citrate buffer, as described in Table 1. After the last bath, the sections were scraped off the slides using a 2.4-cm-diameter glass microfiber filter (Whatman) and placed in $10 \mathrm{ml}$ of Scintiverse E scintillation fluid. After a minimum of $12 \mathrm{hr}$, the sections were counted in a liquid scintillation counter (Beckman Model LS7000). The amount of protein in $20 \mu \mathrm{m}$ tissue 
Table 1. $\mathrm{H}^{3}$-tryptamine binding procedure

\begin{tabular}{cc} 
Bath & Total binding \\
\hline Preincubation I & $0.1 \mathrm{M}$ trizma citrate \\
5 min, $25^{\circ} \mathrm{C}$ & $\mathrm{pH} 7.4$ \\
& $5 \mathrm{mM}$ ascorbic acid \\
Preincubation II & $0.1 \mathrm{M}$ trizma citrate \\
2 min, $25^{\circ} \mathrm{C}$ & $\mathrm{pH} 7.4$ \\
& $5 \mathrm{mM}$ ascorbic acid \\
Incubation bath & $20 \mu \mathrm{M}$ pargyline \\
For binding & $0.1 \mathrm{M}$ trizma citrate \\
$60 \mathrm{~min}, 25^{\circ} \mathrm{C}$ & $\mathrm{pH} 7.4$ \\
For autoradio & $5 \mathrm{mM}$ ascorbic acid \\
$30 \mathrm{~min}, 25^{\circ} \mathrm{C}$ & $20 \mu \mathrm{M}$ pargyline \\
Wash I & $2 \mathrm{nM} \mathrm{H}$-tryptamine \\
6.5 min, $4^{\circ} \mathrm{C}$ & $0.1 \mathrm{M}$ trizma citrate \\
& $\mathrm{pH} 7.4$ \\
Wash II & $5 \mathrm{mM}$ ascorbic acid \\
$6.25 \mathrm{~min}, 4^{\circ} \mathrm{C}$ & $20 \mu \mathrm{M}$ pargyline \\
& $0.1 \mathrm{M}$ trizma citrate \\
& $\mathrm{pH} 7.4$ \\
& $5 \mathrm{mM}$ ascorbic acid \\
& $20 \mu \mathrm{M}$ pargyline
\end{tabular}

Nonspecific binding was measured in the presence of $2 \mu \mathrm{M}$ unlabeled tryptamine.

sections was determined using the Coomassie Brilliant Blue method, as described by Macart and Gerbaut (1982).

For autoradiography, both canine and rodent tissue sections were cut at $20 \mu \mathrm{m}$ and processed according to the protocol described in Table 1 with the exception that tissues were incubated for only $30 \mathrm{~min}$. This shorter incubation time was used because it provided a higher specific/ nonspecific binding ratio. Brains from rats were sectioned from the rostral pole of the forebrain to the caudal medulla. The canine caudal brain stem and spinal cord were also sectioned, incubated and processed for autoradiography. Autoradiography of tissue sections was carried out as described previously (Beitz et al., 1984). After the last bath, sections were briefly dipped in distilled water, dried, and apposed to LKB Ultrofilm. After an appropriate exposure period, the film was developed in D-19 developer and analyzed using a computerized photometer system. Since tritium standards were not used in this analysis, the density values obtained represent relative values for the nuclear groups studied. In addition, no attempt was made to account for the regional whitematter quenching, which varies according to the different ratios of gray to white matter in the brain regions studied (Unnerstall and Kuhar, 1985). Brain structures were identified according to the atlas of Paxinos and Watson (1982) for the rat and of Singer (1962) for the dog.

Tritiated tryptamine hydrochloride, with a specific activity ranging between 23.9 and $41.5 \mathrm{Ci} / \mathrm{mmol}$, was purchased from New England Nuclear. Fluoxetine hydrochloride was a gift from Eli Lilly and Co. (Indianapolis, IN). Lysergic acid diethylamide (LSD) was a gift from The National Institute on Drug Abuse. All other chemicals, unless otherwise stated, were obtained from Sigma Chemical Co. (St. Louis, MO).

\section{Results}

\section{Binding kinetics}

The rate of association of tritiated tryptamine with its binding site was determined by varying the length of the incubation period, while maintaining the bath temperature at $25^{\circ} \mathrm{C} . \mathrm{H}^{3}-$ tryptamine bound rapidly with a half-time of association at 3.8 $\mathrm{min}$ and saturation in approximately $15 \mathrm{~min}$ (Fig. 1). Analysis by linear regression of the same data provides the association rate constant $\left(K_{+1}\right)$ of $0.059 \mathrm{~nm}^{-1} \mathrm{~min}^{-1}$. In contrast, the rate of dissociation of tritiated tryptamine was determined by varying the total wash time while maintaining the wash bath temperature at $4^{\circ} \mathrm{C}$. The half-time of dissociation under these con-

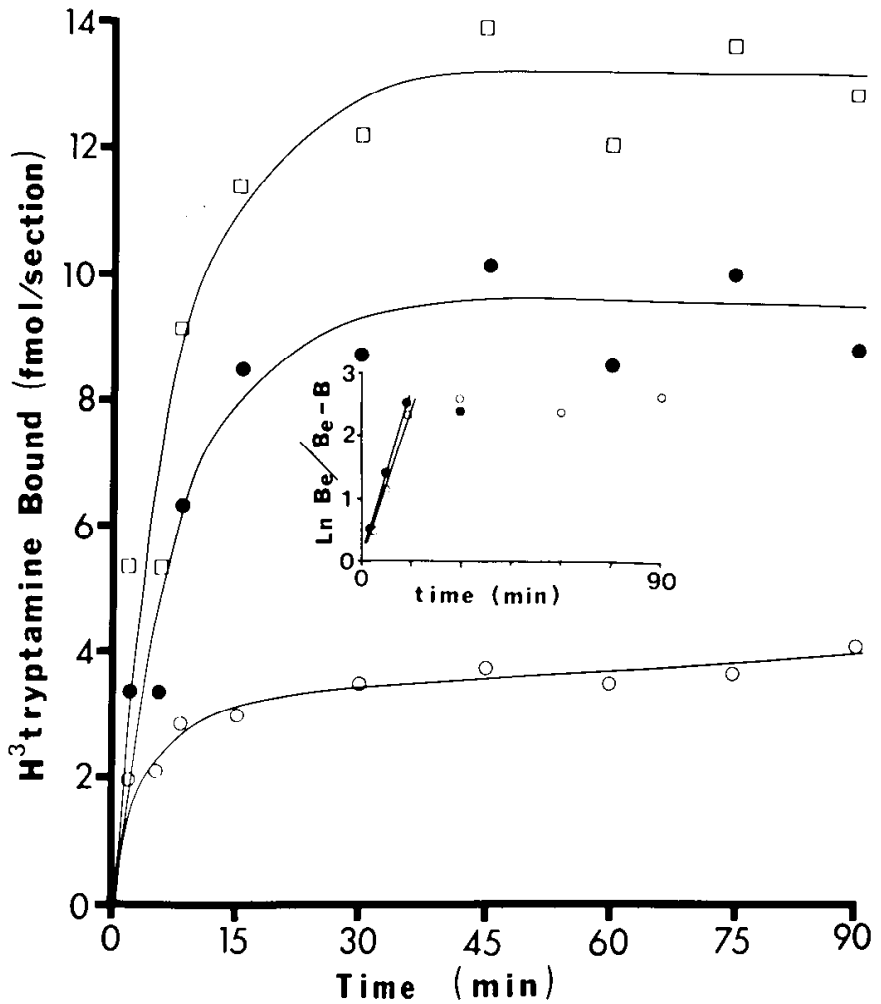

Figure 1. Effect of varying incubation times on the total ( $\square$ ), specific $(\bullet)$, and nonspccific $(O)$ binding of $\mathrm{H}^{3}$-tryptamine to mounted tissue sections. See text for details. Each point represents the average of three or more experiments, except at 75 and 90 min, which are based on two and one experiments, respectively. The insert depicts the association curve, based on linear regression of data in the main graph. The association rate constant was calculated to be $0.059 \mathrm{~nm}^{-1} \mathrm{~min}^{-1}$.

ditions was determined to be $15.5 \mathrm{~min}$ while the dissociation rate constant ( $\left.K_{-1}\right)$ was calculated to be $0.045 \mathrm{~min}^{-1}$ (Fig. 2). If pargyline hydrochloride was omitted, specific $\mathrm{H}^{3}$-tryptamine binding was dramatically reduced because of the rapid oxidation by MAO.

\section{Saturation studies}

Slide-mounted tissue sections were incubated with different concentrations of $\mathrm{H}^{3}$-tryptamine to determine total binding, and also in the presence of excess unlabeled tryptamine (1000-fold excess) to determine nonspecific binding. All sections were incubated for $60 \mathrm{~min}$ to establish equilibrium. This longer incubation bath time was needed primarily at the lower concentrations of tritiated tryptamine. Scatchard analysis of this data (Scatchard plot, Fig. $3 B$ ) suggests an equilibrium dissociation constant $\left(K_{D}\right)$ of $4.79 \pm 1.55 \mathrm{~nm}(n=3$, ranging from 3.12 to $7.89 \mathrm{nM})$ and the maximum number of binding sites $\left(B_{\max }\right)$ was $195 \pm 34 \mathrm{fmol} / \mathrm{mg}$ protein. Linear regression of the data yields a Hill coefficient $\left(n_{\mathrm{H}}\right)$ of $0.97 \pm 0.04$ (Fig. $3 \mathrm{~A}$ ), suggesting binding to a single class of sites and lack of any apparent cooperativity. Previous studies by Cascio and Kellar (1983) have shown saturation of specific tritiated tryptamine binding at 8-10 nм. Owing to the large quantities of radiolabeled tryptamine required in the incubation baths, the concentration required for saturation of specific binding was not determined.

\section{Competition studies}

Various concentrations of the compounds listed in Table 2 were added to both incubation baths to determine their effects on specific $\mathrm{H}^{3}$-tryptamine binding. The changes in the specific binding due to the compounds' competition were analyzed by Logit 


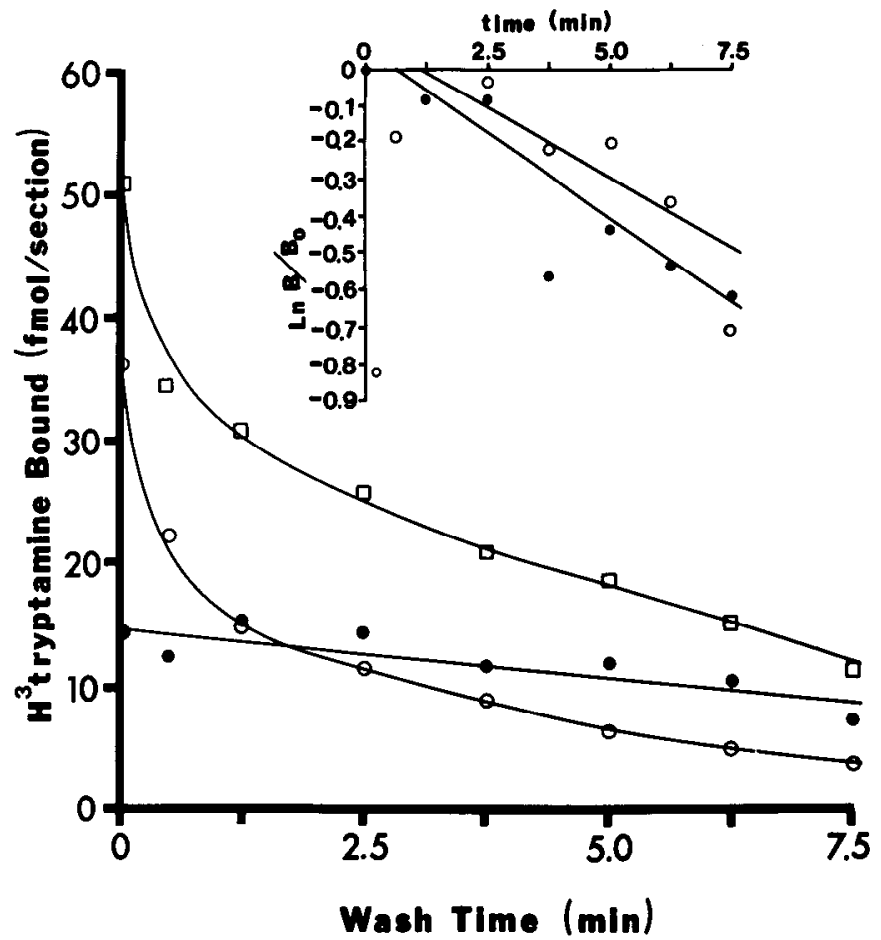

Figure 2. Effect of varying wash times on the total ( $\square$ ), specific (Ө), and nonspecific $(O)$ binding of $\mathrm{H}^{3}$-tryptamine to mounted tissue sections. Results are the average of two or more experiments. The insert depicts the dissociation curve, based on linear regression of data in the main graph. The dissociation rate constant was calculated to be 0.045 $\min ^{-1}$. See text for further details.

Transformation (Rodbard and Frazier, 1975) to determine the concentration of compound required to inhibit $50 \%$ of the specific $\mathrm{H}^{3}$-tryptamine binding $\left(I C_{50}\right)$. As the Hill coefficient was found to be close to 1 for each of the competing drugs, the $I C_{50}$ of each was then converted to an inhibitory constant, $K_{l}$, where $K_{I}=I C_{50} /\left[1+\left(\mathrm{H}^{3}\right.\right.$-tryptamine $\left.) / K_{D}\right]$. The use of $K_{I}$ allows comparison of the abilities of these compounds to inhibit tryptamine binding with previous studies.

Tryptamine hydrochloride had a $K_{I}$ of $4.19 \pm 2.13 \mathrm{nM}$, in agreement with the $K_{D}$ of $4.79 \mathrm{nM}$ for $\mathrm{H}^{3}$-tryptamine, indicating a similar affinity of these ligands for the binding sites (Table 2). Tryptophan, the precursor to tryptamine, and indoleacetic acid, an endogenously formed metabolite of tryptamine, both lacked the ability to inhibit specific $\mathrm{H}^{3}$-tryptamine binding at all concentrations tested. On the other hand, other metabolic products

\section{Table 2. Competition studies: inhibitory constants}

Compound

Tryptamine $\cdot \mathrm{HCl}$

Tryptophan (D and $\mathrm{L}$ isomers)

Indole-3-acetic acid

Kynuramine $\cdot$ dihydrobromide

Tetrahydrobetacarboline $\cdot \mathrm{HCl}$ (Tryptoline)

5-Hydroxytryptamine $\cdot$ oxalate (Serotonin)

Lysergic acid diethylamide

Fluoxetine $\cdot \mathrm{HCl}$

beta-Phenylethylamine $\cdot \mathrm{HCl}$

5 -Hydroxytyramine $\cdot \mathrm{HCl}$ (Dopamine)

gamma-Aminobutyric acid

Diazepam

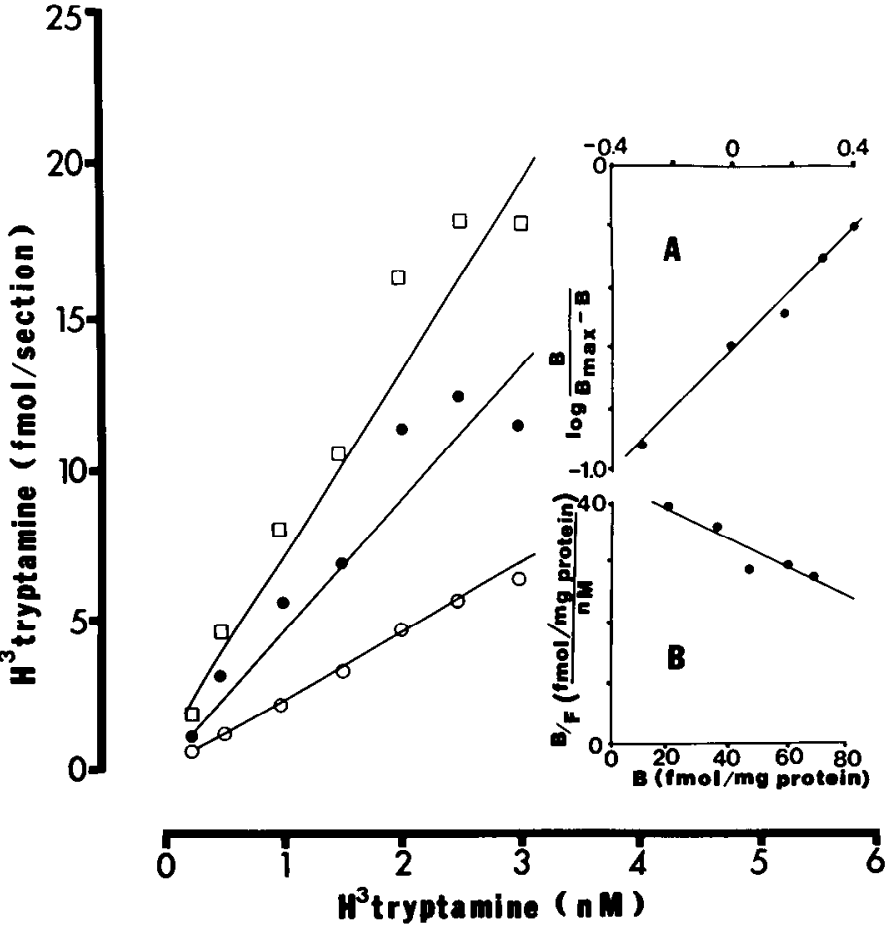

Figure 3. Representative saturation and Scatchard plots of $\mathrm{H}^{3}$-tryptamine binding to mounted brain tissue sections. Each point represents the average of two to six experiments. Insert $A$ shows an analysis of the data using the Hill plot, which yields a $K_{D}$ of $4.0437 \mathrm{~nm}$ and a $B_{\max }$ of $174.9931 \mathrm{fmol} / \mathrm{mg}$ protein. Insert $B$ shows an analysis of the data using the Rosenthal (Scatchard) analysis, which yields a $K_{D}$ of $4.0729 \mathrm{nM}$. Open squares indicate total binding, closed circles indicate specific binding, and open circles indicate nonspecific binding. See text for further details.

of tryptamine, such as kynuramine and tetrahydrobetacarboline, had $K$, values of 27.01 and $70.68 \mathrm{nM}$, respectively, indicating high affinities for the tryptamine binding site. Compounds previously reported to affect serotonin binding showed little ability to inhibit tryptamine binding. Serotonin itself produced a $K_{l}$ of $1620 \mathrm{~nm}$, while fluoxetine, a serotonin uptake inhibitor, yielded a $K_{I}$ of $3490 \mathrm{~nm}$. At concentrations up to 100 $\mu \mathrm{M}$, LSD, a commonly used ligand for serotonin binding sites, did not inhibit $\mathrm{H}^{3}$-tryptamine binding, implying a $K_{I}$ of greater than $70,000 \mathrm{nM}$. Other drugs inhibiting $\mathrm{H}^{3}$-tryptamine binding include dopamine and phenylalanine, both producing $K_{I}$ values comparable to that of serotonin -4000 and $1480 \mathrm{nM}$, respectively. Gamma-aminobutyric acid and diazepam were ineffective in displacing $\mathrm{H}^{3}$-tryptamine at concentrations up to 200 $\mu \mathrm{M}$, implying $K_{I}$ values of greater than $100,000 \mathrm{nM}$.

\section{Autoradiography studies}

The relative density values obtained from autoradiographic images are shown in Table 3 for the rat and Table 4 for the dog. Each specific photometer reading indicates the decrease in percentage of transmittance and thereby represents the relative density of specific $\mathrm{H}^{3}$-tryptamine binding. Nonspecific binding was found to be relatively homogeneous throughout the brain and spinal cord. Each value represents the mean of three animals and was calculated by subtracting the nonspecific binding and background film density from the total binding.

\section{Telencephalon (Figs. 4 and 5, Table 3)}

Tryptamine binding sites were densest in the limbic structures. The highest values were found in the frontal cortex, entorhinal cortex, nucleus accumbens, lateral septal area, anterior olfactory 
Table 3. Density (in arbitrary optical density units) of specific $\mathbf{H}^{3}$ tryptamine binding in various brain regions of the rat

Brain region

Accumbens nucleus

Amygdalohippocampal area

Density $\quad \pm \mathrm{SE} \quad n^{a}$

Cortex

Frontal

Entorhinal

Medial frontal

Primary olfactory

Anterior cingulate

Retrosplenial

Frontoparietal-motor area -somatosensory

Temporal, auditory area

Area 17 (striate)

Area 18 (striate)

Posterior cingulate

Islands of Calleja

Lateral septal nucleus

Bed nucleus of stria terminalis

Anterior olfactory nucleus

Septohippocampal nucleus

Olfactory tubercle

Amygdaloid nuclei

Medial septal nucleus

Hippocampus

Caudate putamen (striatum)

Ventral pallidum

Dentate gyrus

Globus pallidus

Diencephalon

Thalamus

$\begin{array}{lrrr}\text { Reuniens nucleus } & 30.0 & 7.7 & 4 \\ \text { Paraventricular nucleus } & 29.3 & 5.7 & 4 \\ \text { Central medial nucleus } & 25.6 & 4.6 & 4 \\ \text { Paratenial nucleus } & 24.8 & 11.4 & 2 \\ \text { Mediodorsal nucleus } & 21.6 & 2.2 & 4 \\ \text { Lateral posterio nucleus } & 21.2 & 3.3 & 4 \\ \text { Dorsal lateral geniculate } \mathrm{n} . & 19.7 & 3.3 & 4 \\ \text { Stria medullanis of thalamus } & 19.0 & 5.1 & 4 \\ \text { Posterior nuclear group } & 16.4 & 3.8 & 4 \\ \text { Laterodorsal thalamic nucleus } & 15.4 & 4.5 & 4 \\ \text { Medial geniculate nucleus } & 15.3 & 4.3 & 4 \\ \text { Ventromedial thalamic nucleus } & 15.0 & 6.5 & 2 \\ \text { Ventrolateral thalamic nucleus } & 14.0 & 7.6 & 3 \\ \text { Reticular thalamic nucleus } & 10.1 & 4.6 & 4 \\ \text { Ventral lateral geniculate } \mathrm{n} . & 9.7 & 3.6 & 3 \\ \text { Hypothalamus } & & & \\ \text { Arcuate nucleus } & & & \\ \text { Periventricular nucleus } & 26.0 & 6.6 & 4 \\ \text { Dorsomedial nucleus } & 23.6 & 6.2 & 4 \\ \text { Posterior nucleus } & 23.4 & 6.2 & 4 \\ \text { Medial preoptic area } & 22.8 & 6.9 & 3 \\ \text { Ventromedial hypothalmic n. } & 21.8 & 2.6 & 4 \\ \text { Lateral preoptic area } & 20.6 & 6.9 & 4 \\ \end{array}$

6.54

$\begin{array}{lll}29.2 & 7.7 & 3\end{array}$

$28.6 \quad 3.1$

26.0

24.2

24.0

23.6

22.4

22.0

19.4

19.0

35.1

32.0

31.6

31.2

31.1

30.0

27.0

26.1

25.1

23.6

23.1

19.4

16.2

3.1

3.3

5.0

5.7

7.8

4.5

4.6

2.7

5.1

5.1

4

5.4

2.0

8.8

5.0

5.3

3.6

3.0

1.7

4.0

3.3

2.0
Table 3. Continued

Brain region

Lateral hypothalamic nucleus

Supra mammillary nucleus

Mammillary nucleus

Subthalamus: Zona incerta

Epithalamus

Medial habenular nucleus

Lateral habenular nucleus

Mesencephalon

Zonal layer of sup. colliculus

Superior colliculus

Interpeduncular nucleus

Periaqueductal gray

Paranigral nucleus

Ventral tegmental area

Substantia nigra

Median raphe nucleus

Rostral linear $n$. of raphe

Deep mesencephalic nucleus

Red nucleus

\begin{tabular}{ccc} 
Density & $\pm \mathrm{SE}$ & $n^{a}$ \\
\hline 16.8 & 5.4 & 4 \\
12.1 & 2.6 & 3 \\
11.8 & 3.0 & 3 \\
9.3 & 3.3 & 4
\end{tabular}

25.8

4.2

4.1

25.6

22.8

20.6

19.0

18.4

15.7

15.6

15.5

13.5

11.2

7.5

\section{7}

3.3

$$
2.2
$$

$$
7.5
$$

$$
4.8
$$

$$
4.3
$$

$$
5.0
$$

Myelencephalon

Pons

Pontine nuclei

Locus coeruleus

17.2

Pontine reticular $\mathrm{n}$. oral part

Dorsal tegmental nucleus

Reticulo tegmental $\mathbf{n}$. of pons

Nucleus of trapezoid body

Central gray of the pons

Dorsal parabarchial nucleus

Principal sensory trigeminal $\mathbf{n}$.

Motor trigeminal nucleus

Pontine ret. $\mathbf{n}$. caudal part

Superior olive

Raphe pontis

14.3

13.0

12.2

10.7

Medulla

Vestibular nucleus

Prepositus hypoglossal nucleus

External cuneate nucleus

Dorsal motor $\mathrm{n}$. of vagus

Spinal trigeminal $n$. oral part

Dorsal cochlear nucleus

Nucleus of solitary tract

Hypoglossal nucleus

Spinal trigeminal n. caudal part

Parvocellular reticular $\mathbf{n}$.

Facial nucleus

Gracile nucleus

Spinal trig. $n$. interpolaris

Ventral cochlear nucleus

Pyramidal tract.

Gigantocellular reticular $\mathbf{n}$.

Paramedian reticular nucleus

Lateral reticular nucleus

Inferior olive

Raphe pallidus

$\begin{array}{rll}11.7 & 2.4 & 4 \\ 9.6 & 3.8 & 4 \\ 9.4 & 4.4 & 2 \\ 8.9 & 5.7 & 4 \\ 8.8 & 2.5 & 4 \\ 8.2 & 2.9 & 3 \\ 7.4 & 2.1 & 4 \\ 7.2 & 2.6 & 4 \\ 4.8 & 8.0 & 2 \\ 4.4 & 0.8 & 4 \\ 4.1 & 6.4 & 3 \\ 3.8 & 6.5 & 2 \\ 3.8 & 1.5 & 4 \\ 3.6 & 1.8 & 2 \\ 1.2 & 2.3 & 4 \\ b & - & 4 \\ b & - & 3 \\ b & - & 3 \\ b & - & 4 \\ b & - & 4\end{array}$




\begin{tabular}{lccc}
\hline Table 3. Continued & & & \\
Brain region & Density & \pm SE & $n^{\alpha}$ \\
\hline Raphe obscurus & $b$ & - & 4 \\
Ambiguus nucleus & $b$ & - & 4 \\
Lateral cervical nucleus & $b$ & - & 4 \\
Cerebellum & & & \\
$\quad$ Molecular layer & 12.4 & 1.8 & 4 \\
Granular layer & 11.4 & 2.4 & 4 \\
$\quad$ Interpositus nucleus & 2.2 & 4.0 & 3 \\
Choroid plexus & 26.2 & 2.6 & 4
\end{tabular}

a $n$ refers to the number of sections from each of the three animals from which density values were obtained.

${ }^{b}$ Indicates average densities are no greater than background.

nucleus, and the amygdalohippocampal area. Moderate binding was seen in the amygdala, choroid plexus, striatum, hippocampus, temporal cortex, anterior cingulate gyrus, and the motor and somatosensory areas of the frontoparietal cortex. Compared to the areas listed above, binding was low in areas such as the globus pallidus and corpus callosum.

\section{Diencephalon (Figs. 4 and 5, Table 3)}

Within the hypothalamus, the highest binding occurred in the arcuate nucleus, the dorsomedial nucleus, and the periventricular nucleus. Moderate binding was observed in the medial and lateral preoptic areas and in the ventromedial nucleus. Tryptamine binding in the thalamus was highest in the reuniens nucleus, the paraventricular nucleus, and the central medial nucleus. In contrast, the ventrolateral and ventromedial thalamic nuclei, as well as the reticular nucleus, showed low levels of binding. Within the epithalamus, both the medial and lateral habenular nuclei exhibited high binding densities.

\section{Mesencephalon (Figs. 4 and 5, Table 3)}

The highest binding occurred in the zonal layer of the superior colliculus, the interpeduncular nucleus and the periaqueductal gray. Binding was substantially lower in the red nucleus and reticular formation.

\section{Myelencephalon and spinal cord (Fig. 6, Tables 3 and 4)}

Within the pons and medulla of the rat brain stem, the highest binding occurred in the pontine nuclei, the pontine reticular nucleus (pars oralis), the locus coeruleus and the dorsal tegmental nucleus. In the medulla of the dog, binding was generally high in areas similar to those in the rat. The highest binding in the medulla of the dog was present in the external cuneate nucleus, spinal trigeminal nucleus, gracile nucleus, hypoglossal nucleus, solitary nucleus, and parvocellular reticular nucleus. Bind- ing was low in the gigantocellular reticular nucleus and the inferior olivary nucleus. White-matter tracts exhibited binding similar to or slightly greater than that of the background.

Within the spinal cord, tryptamine binding sites were present throughout the gray matter, being highest in the areas of the dorsal and intermediate horns (Fig. 6 and Table 4). When analyzed by rostral-caudal segments, binding was highest in the lumbosacral segments of the cord and lowest in the lower cervical region.

\section{Discussion}

The present investigation, using in vitro autoradiographic techniques, confirms the studies using tissue homogenates (Cascio and Kellar, 1982, 1983), indicating that the brain contains specific high-affinity binding sites for $\mathrm{H}^{3}$-tryptamine. This method was developed by Young and Kuhar (1979) and has been successfully used to study gamma-aminobutyric acid, serotonin, adrenergic, muscarinic, and opioid binding sites. The results of our kinetic studies showing rapid association and dissociation, the high-specific affinity for labeled and unlabeled tryptamine, and the autoradiographic distribution strongly suggest that the binding observed is a recognition site for tryptamine. The $K_{D}$ obtained in the present study is remarkably similar to that obtained by Cascio and Kellar (1983).

Our competition studies distinguish this binding site from other binding sites of known and putative neurotransmitters such as serotonin, dopamine, gamma-aminobutyric acid, and phenylethylamine. The precursors D- and L-tryptophan, and the metabolite, indoleacetic acid, failed to inhibit tryptamine binding. However kynuramine, also an endogenous tryptamine metabolite, was found to be a potent inhibitor of tryptamine binding, as previously shown by Charlton et al. (1984) using tissue homogenate preparations. Similarly, another endogenous metabolite of tryptamine, tetrahydrobetacarboline, was found to be a fairly potent displacer of tryptamine binding, as was reported previously by several other investigators using homogenate preparations (Cascio and Kellar, 1982; Rommelspacher and Kaufmann, 1983; Wood et al., 1984).

Serotonin, whose three-dimensional structure is similar to tryptamine, was found to be only a weak inhibitor of $\mathrm{H}^{3}$-tryptamine binding, suggesting a class of binding sites distinct from those of serotonin. LSD, a commonly used ligand in serotonin binding studies, failed to inhibit tryplamine binding. Fluoxetine, a serotonin reuptake inhibitor, was as ineffective as serotonin in inhibiting tryptamine binding; it would thus appear that the tryptamine binding site is distinct from both the LSD and serotonin binding site and the serotonin reuptake site.

Phenylethylamine (PEA) has been previously reported to displace $\mathrm{H}^{3}$-tryptamine in tissue homogenate studies (Cascio and Kellar, 1983). Our results confirm the ability of PEA to displace $\mathrm{H}^{3}$-tryptamine binding. A recent abstract presented by Martin et al. (1984) comparing various PEA derivatives indicates that

Table 4. Density (in arbitrary optical density units) of specific $\mathbf{H}^{3}$-tryptamine binding in varlous segments of the spinal cord of the dog

\begin{tabular}{lccccc}
$\begin{array}{l}\text { Cord region } \\
\text { (lamina no.) }\end{array}$ & Density $( \pm \mathrm{SE})$ & & & \\
\cline { 2 - 6 } & Upper cervical & Lower cervical & Mid-thoracic & Upper lumbar & Lumbo-sacral \\
\hline Superficial (I, II) & $9.1 \pm 6.3$ & $2.9 \pm 3.5$ & $8.9 \pm 6.1$ & $9.5 \pm 8.5$ & $14.5 \pm 3.1$ \\
Dorsal (III, IV, V) & $12.0 \pm 5.2$ & $6.7 \pm 3.1$ & $14.2 \pm 5.4$ & $14.2 \pm 10.7$ & $22.4 \pm 6.5$ \\
Intermediate (VI) & - & $12.9 \pm 4.6$ & $13.1 \pm 4.7$ & $10.2 \pm 5.0$ & $19.0 \pm 4.9$ \\
Ventral (VII, VIII, IX) & $10.3 \pm 4.9$ & $7.0 \pm 3.8$ & $9.6 \pm 1.8$ & $14.8 \pm 11.0$ & $16.5 \pm 4.4$ \\
Central (X) & $12.0 \pm 6.1$ & $6.6 \pm 4.3$ & $7.4 \pm 2.0$ & $14.4 \pm 12.4$ & $14.0 \pm 6.0$ \\
Ventral funiculus & $4.6 \pm 3.0$ & $-1.7 \pm 3.1$ & $0.8 \pm 3.2$ & $1.4 \pm 3.4$ & $7.2 \pm 1.4$ \\
\hline
\end{tabular}

The above density values were obtained from three dogs. 


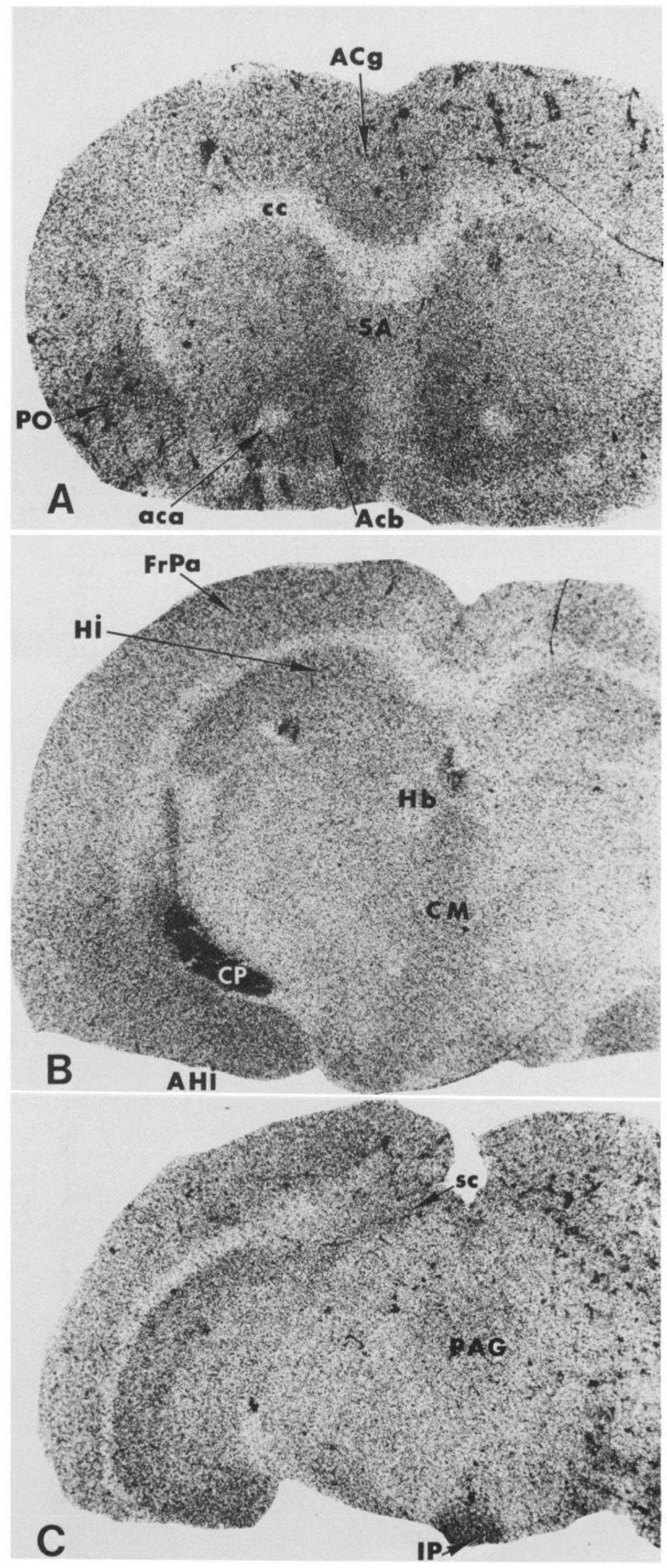

Figure 4. Representative autoradiographic images of $\mathrm{H}^{3}$-tryptamine binding from the forebrain $(A)$, diencephalon $(B)$ and midbrain $(C)$ in the rat. Images $A, B$, and $C$ correspond to Figs. 12, 22, and 26 in the atlas of Paxinos and Watson (1982). Image $A$ shows high binding densities in the anterior cingulate cortex $(A C g)$, the accumbens nucleus $(A c b)$, the septal area $(S A)$, and the primary olfactory cortex $(P O)$. The corpus callosum $(c c)$ and anterior commissure ( $a c a$ ) are also shown. $B$, High tryptamine binding in the choroid plexus of the lateral ventricle $(C P)$, the motor area of the frontoparietal cortex $(\mathrm{FrPa})$, the hippocampus $(\mathrm{Hi})$, the amygdalohippocampal area $(A H i)$, the habenular nuclei $(H b)$, and the central medial nucleus $(C M)$. Tryptamine binding in the midbrain, $C$, is highest in the superficial layer of the superior colliculus $(s c)$, the interpeduncular nucleus $(I P)$, and the periaqueductal gray $(P A G)$. 

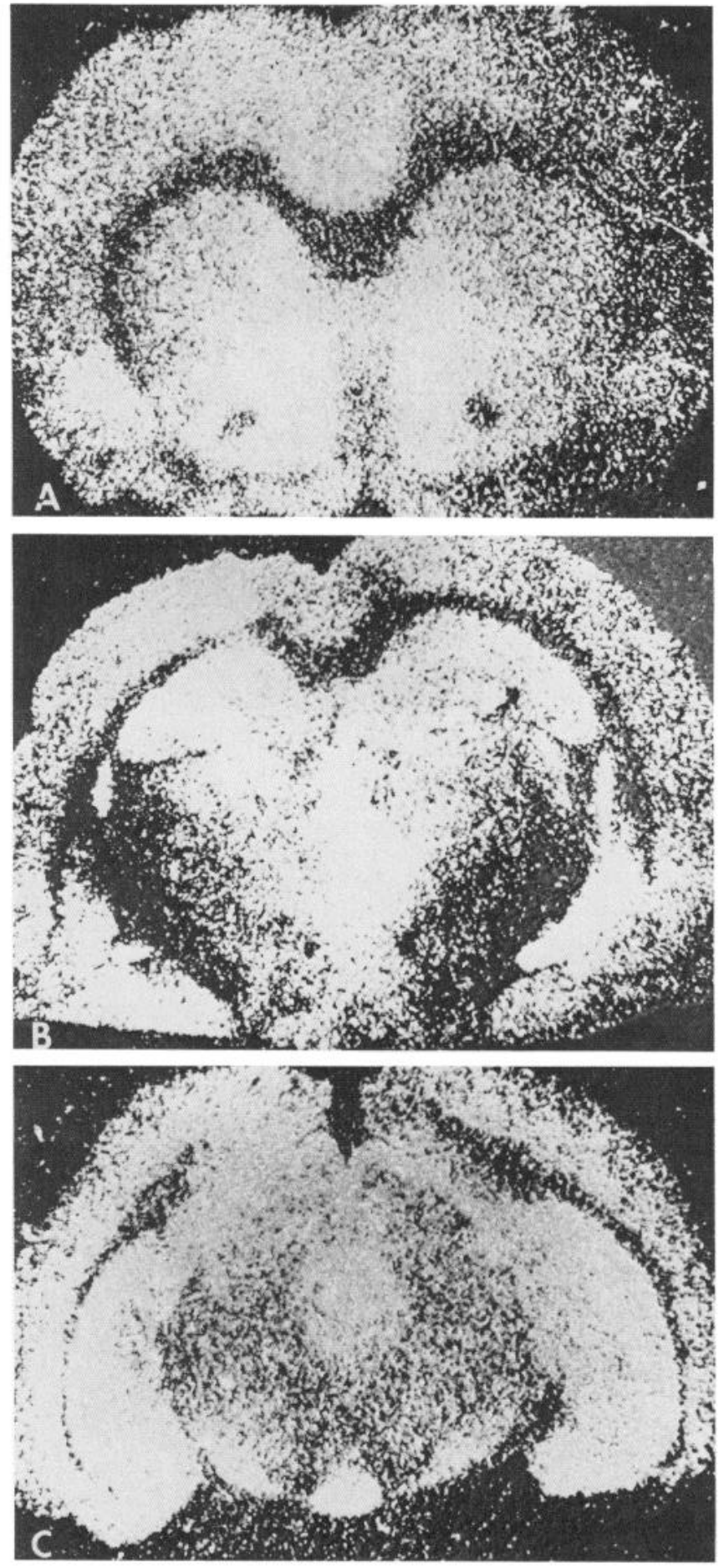

Figure 5. Computer-enhanced images of the three autoradiograms shown in Figure 4. The highest binding is illustrated in white and areas of lower binding in darker shades. A computerized image analysis system was used, as described previously (Beitz and Buggy, 1981).

para-methoxyphenylpropylamine is the most potent displacer of $\mathrm{H}^{3}$-tryptamine. By comparing the abilities of these PEA derivatives, they concluded that the tryptamine binding site is composed of a large flat lipophilic site that lies distal to an anionic site.

The in vitro autoradiographic localization of $\mathrm{H}^{3}$-tryptamine binding sites in the rat brain was first reported by Perry et al. (1982); they reported binding to be highest in the areas of the striatum, hippocampus, and cortex. Our results also indicate that binding is highest in the limbic structures and cortex, cor-

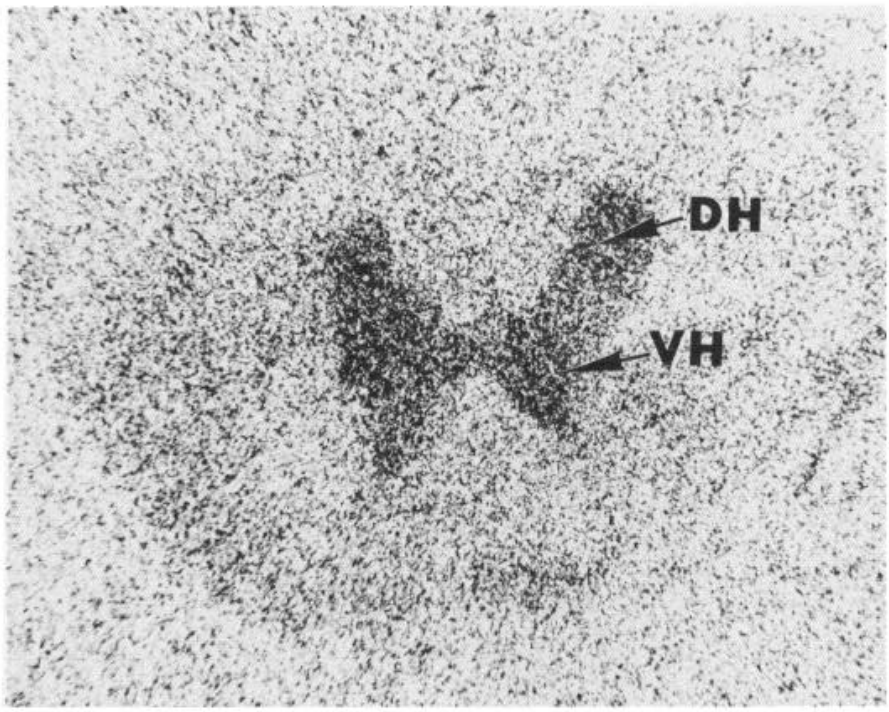

Figure 6. Representative autoradiographic image of $\mathrm{H}^{3}$-tryptamine binding in the ventral $(\mathrm{VH})$ and dorsal $(\mathrm{DH})$ horns of the thoracic region of the canine spinal cord. This image illustrates the high binding in gray matter relative to the surrounding white matter. In general, binding to white-matter structures was no greater than to background.

relating well with this initial autoradiographic study as well as with studies in which the binding was examined in homogenates of various brain regions (Cascio and Kellar, 1983; Wood et al., 1984). In general, tryptamine binding appears to be highest in more rostral structures and decreases progressively toward the more caudal brain areas. While the $\mathrm{H}^{3}$-tryptamine binding sites are distinct from those of serotonin, there appears to be some overlap in the distribution of the binding sites of these two indoleamines-for example, in cortical and hippocampal regions (Bigeon et al., 1982; Nakada et al., 1984; Palacios et al.,

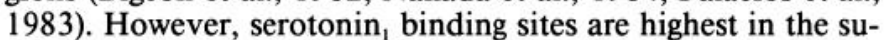

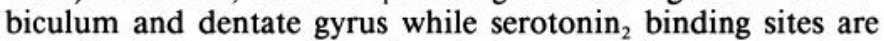
found in highest concentrations in the cerebral cortex, caudateputamen, nucleus accumbens, mammillary nucleus, and the inferior olive. In the present study, tryptamine binding sites are most dense in the nucleus accumbens, the amygdalohippocampal area, and the cerebral cortex, where they appear to overlap with the distribution of serotonin ${ }_{2}$ binding sites. However, tryptamine binding sites are low in mammillary nuclei and nondetectable in the inferior olivary nucleus, indicating differences between serotonin, and tryptamine binding sites.

The use of the dog for the autoradiographic localization of $\mathrm{H}^{3}$-tryptamine binding allows even greater delineation of areas containing tryptamine binding sites because of the large size of the canine spinal cord and brain stem. Tryptamine binding was found to be relatively low in canine spinal structures. A comparison of binding densities between the rat and the dog indicates that tryptamine binding sites are distributed in similar areas of the medulla in these two species.

The anatomical distribution of tryptamine binding sites in the CNS and the high degree of pharmacologic specificity of agents in their ability to inhibit this binding suggest that the $\mathrm{H}^{3}$ tryptamine binding site may be a receptor for tryptamine. The physiologic significance of the ability of kynuramine, tetrahydrobetacarboline and PEA to inhibit $\mathrm{H}^{3}$-tryptamine binding remains obscure.

As tryptamine has a high affinity for $\mathrm{H}^{3}$-tryptamine binding sites, a differential distribution of endogenously formed tryptamine could potentially result in a local inhibition of labeled tryptamine binding, thus falsifying the distribution of regional binding sites. However, one would expect this effect to be min- 
imal in the brain and spinal cord, as mass spectrum analysis indicates that tryptamine is found in very low concentrations in this tissue (Philips et al., 1974) relative to the concentration necessary to displace a significant amount of labeled tryptamine. In addition, much of the endogenously formed tryptamine would be metabolized or diffuse from the tissue during the $5 \mathrm{~min}$ preincubation period. Since tryptamine undergoes an exceptionally rapid metabolism compared either to serotonin or norepinephrine, it is unlikely that endogenous tryptamine is present in sufficient amounts to affect the binding of tritiated tryptamine in the present study.

The concentration of endogenous tryptamine has been generally found to bc highest in the caudate, hippocampus, and hypothalamus and lowest in the brain stem and cerebellum (Jones, 1982; Philips et al., 1974). This distribution of indoleamine correlates well with the distribution of binding reported in the present study, showing high binding in the limbic system and striatum and the lowest binding in the cerebellum and lower brain stem. It has been previously proposed that tryptamine acts in the CNS to modulate the activity of serotonin (Jones and Boulton, 1980). Other studies have shown that tryptamine produces effects that are opposite to those produced by serotonin on the C-fiber reflex, mono- and polysynaptic reflexes (Bell and Martin, 1974), and nociceptive activity after its intrathecal injection in conscious rats (Larson, 1983). This is consistent with our finding of $\mathrm{H}^{3}$-tryptamine binding sites in the dorsal and ventral horns of the spinal cord. The present study shows the highest density of $\mathrm{H}^{3}$-tryptamine binding sites in the nucleus accumbens. A recent report indicates that injection of tryptamine into this region evokes intense locomotor activity (Altar et al., 1985). In addition to its effects on locomotion, tryptamine has also been implicated in various psychiatric disorders and physiological functions, as reviewed by Jones (1982).

\section{References}

Altar, C. A., B. Boyar, and L. L. Martin (1985) Tryptamine and serotonin receptor autoradiography: Distinct pharmacology and localization in brain. J. Neurochem. 44: 540.

Beitz, A. J., and J. Buggy (1981) Brain functional activity during PAG stimulation-produced analgesia: A 2-DG study. Brain Res. Bull. 6: $487-494$

Beitz, A. J., J. Buggy, T. F. Fletcher, and L. Weiner. (1984) Muscarinic cholinergic receptors in the rat deep cerebellar nuclei: A quantitative autoradiographic study. Ncurosci. Lett. 50: 103-109.

Bell, J. A., and W. R. Martin (1974) Studies of tryptamine and lysergic acid diethylamide (LSD) on cutaneous C-fiber and polysnyaptic reflexes in the cat. J. Pharmacol. Exp. Ther. 190: 492-500.

Bigeon, A., T. C. Rainbow, and B. S. McEwen (1982) Quantitative autoradiography of serotonin receptors in the rat brain. Brain Res. 242: 197-204.

Cascio, C. S., and K. J. Kellar (1982) Tetrahydro-beta-carbolines: Affinities for tryptamine and serotonergic binding sites. Neuropharmacology 21: 1219-1221.

Cascio, C.S., and K. J. Kellar (1983) Characterization of $\left[{ }^{3} \mathrm{H}\right]$ tryptamine binding sites in brain. Eur. J. Pharmacol. 95: 31-39.

Charlton, K. G., K. Ghansali, T. D. Johnson, and D. E. Clarke (1984) Inhibition of $\left[{ }^{3} \mathrm{H}\right]$ tryptamine binding by kynuramine, an endogenous metabolite of tryptophan: Neurochemical profile and structure activity relationships. Fed. Proc. 43: 745 (Abstr. 2691).

Frankhuijzen, A. L., and I. L. Bonta (1974) Receptors involved in the action of 5-HT and tryptamine on the isolated rat stomach fundus preparation. Eur. J. Pharmacol. 26: 220-230.

Jones, R. S. G. (1982) Tryptamine: A neuromodulator or neurotransmitter in mammalian brain? Prog. Neurobiol. 19: 117-139.
Jones, R. S. G., and A. A. Boulton (1980) Tryptamine and 5-hydroxytryptamine: Actions and interactions on cortical neurons in the rat. Life Sci. 27: 1849-1856.

Kellar, K. J., and C. S. Cascio (1982) $\left[{ }^{3} \mathrm{H}\right]$ Tryptamine: High affinity binding sites in the rat brain. Eur. J. Pharmacol. 78: 475-478.

Larson, A. A. (1983) Hyperalgesia produced by the intrathecal administration of tryptamine to rats. Brain Res. 265: 109-117.

Macart, M., and L. Gerbaut (1982) An improvement of the Coomassie Blue dye binding method allowing an equal sensitivity to various proteins: Application to cerebrospinal fluid. Clinica Chimica Acta 122: 93-101.

Marsden, C. A., and G. Curzon (1974) Effects of lesions and drugs on brain tryptamine. J. Neurochem. 23: 1171-1176.

Martin, L. L., D. M. Roland, R. F. Neale, and P. L. Wood (1984) ${ }^{3}$ HTryptamine binding in rat brain: Effects of phenylalkylamine derivatives. Pharmacologist 26: 135 (Abstr. 53).

Martin, W. R., J. W. Sloan, J. W. Christian, and T. H. Clements (1972) Brain levels of tryptamine. Psychopharmacology 24: 331-346.

McCormack, J. K., A. J. Beitz, and A. A. Larson (1983) ${ }^{3}$ H-Tryptamine binding in the brain and spinal cord: In vitro autoradiography. Neurosci. (Abstr. 101.2): 9: 333.

Nakada, M. T., C. M. Wieczorek, and T. C. Rainbow (1984) Localization and characterization by quantitative autoradiography of [ $\left.{ }^{25} \mathrm{I}\right]$ LSD binding sites in rat brain. Neurosci. Lett. 49: 13-18.

Palacios, J. M., A. Probst, and R. Cortes (1983) The distribution of serotonin receptors in the human brain: High density of $\left[{ }^{3} \mathrm{H}\right] \mathrm{LSD}$ binding sites in the raphe nuclei of the brainstem. Brain Res. 274: 150-155.

Paxinos, G., and C. Watson (1982) The Rat Brain in Stereotaxic Coordinates, Academic, New York.

Perry, D. C., D. C. Manning, and S. H. Snyder (1982) In vitro autoradiographic localization of $\left[{ }^{3} \mathrm{H}\right]$ tryptamine binding sites in rat brain. Neuroscience 8: 783 (Abstr. 223.13).

Philips, S. R., A. Durden, and A. A. Boulton (1974) Identification and distribution of tryptamine in the rat. Can. J. Biochem. 52: 447-451.

Quock, R. M., and B. G. Weick (1978) Tryptamine-induced drug effects insensitive to serotonin antagonists: Evidence of specific tryptaminergic receptor stimulation? J. Pharm. Pharmacol. 30: 280-283.

Rodbard, D., and G. H. R. Frazier (1975) Statistical analysis of radioligand assay data. Methods Enzymol. 37B: 3-22.

Rommelspacher, H., and G. Kaufmann (1983) High affinity binding sites of $\left[{ }^{3} \mathrm{H}\right]$ tetrahydronorharmane (tetrahydro-beta-carboline) and $\left[{ }^{3} \mathrm{H}\right]$ tryptamine on brain membranes of rats. Naunyn-Schmiedeberg's Arch. Pharmacol. 322: Abstr. 367.

Saavedra, J. M., and J. Axelrod (1972) A specific and sensitive enzymatic assay for tryptamine in tissues. J. Pharmacol. Exp. Ther. 182. 363-369.

Singer, M. (1962) The Brain of the Dog in Section, W. B. Saunders, Philadelphia, PA.

Sloan, J. W., W. R. Martin, T. H. Clements, W. F. Buchwald, and S. $R$. Bridges (1975) Factors affecting brain and tissue levels of tryptamine: Species, drugs and lesions. J. Neurochem. 24: 523-532.

Snodgrass, S. R., and A. S. Horn (1973) An assay procedure for tryptamine in brain and spinal cord using its $\left[{ }^{3} \mathrm{H}\right]$-dansyl derivative. J. Neurochem. 21: 687-696.

Unnerstall, J. R., and M. J. Kuhar (1985) Quantitative receptor mapping by autoradiography: Some current technical problems. Trends Neurosci. 8: 49-53.

Vane, J. R., H. O. J. Collier, S. J. Corne, E. Marley, and P. B. Bradley (1961) Tryptamine receptors in the central nervous system. Nature 4793: 1068-1069.

Wood, P. L., C. Pilapil, F. LaFaille, N. P. V. Nair, and R. A. Glennon (1984) Unique $\left[{ }^{3} \mathrm{H}\right]$ tryptamine binding sites in rat brain: Distribution and pharmacology. Arch. Int. Pharmacodyn. Ther. 268: 194-201.

Young, W. S., and M. J. Kuhar (1979) A new method for receptor autoradiography: $\left[{ }^{3} \mathrm{H}\right]$ opioid receptors in rat brain. Brain Res. 179: 255-270. 